Proceedings

\title{
Analysis of the Psychometric Properties of the Nursing Stress Scale (NSS) in a Spanish Sample. ${ }^{+}$
}

\author{
Marta Peña ${ }^{1}$, Cristina García-Ael ${ }^{2}$ and Gabriela Topa ${ }^{2, *}$ \\ 1 martapr.psicologa@gmail.com \\ 2 UNED; cgarciaael@psi.uned.es, gtopa@psi.uned.es \\ * Correspondence: martapr.psicologa@gmail.com
}

Publisher's Note: MDPI stays neutral with regard to jurisdictional claims in published maps and institutional affiliations.

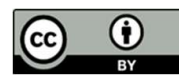

Copyright: $(2020$ by the authors. Submitted for possible open access publication under the terms and conditions of the Creative Commons Attribution (CC BY) license (http://creativecommons.org/licenses/by/4.0/).

\begin{abstract}
NSS by Gray-Toft and Anderson (1981) specifically assesses the stress experienced by nurses. It consists of 34 items that are divided into 7 subscales. The sample consists of 180 nurses. After confirming a high reliability, a CFA confirmed a seven-factor structure. Evidence of the convergent and divergent validity of the seven subscales was provided by the variable job satisfaction. Engagement was not related to two subscales. Discriminant validity (age) showed that the correlations were significant except for "lack of staff support". It is important to have valid and reliable instruments that provide a good evaluation of that variable in a Spanish sample.
\end{abstract}

Keywords: Nursing Stress Scale; Health; Stress

\section{Introduction}

In general, occupational stress is the consequence of the pressures that work circumstances cause on the individual. Nursing is a job where many extreme situations occur. Nurses suffer the usual work environment and also, their job itself is very demanding because they work with sick people and facing death on a daily basis. Thus, one of the most studied variables in nursing professionals is job stress, having created specific tests to measure this variable in this specific population. This is the case of the Nursing Stress Scale (NSS) created by Gray and Anderson (1981) [1]. This scale has been validated in India [2] which made minor changes with the items and confirmed psychometric properties, China [3] which confirmed properties as the original study and Mexico [4] which confirmed good proprieties but only with four factors.

On the other hand, job satisfaction is the positive feeling produced with the conditions of employment and with the work itself. Although nurses work with illness and death, the nursing profession is very satisfying because they also manage to give patients health and quality of life, which is very rewarding for the professionals. Relating job stress and job satisfaction, an inverse relationship in nursing professionals is found [5]. On the other hand, engagement is defined from positive organisational psychology with concepts such as vigour, dedication, and absorption [6]. People with engagement are energetic and capable of responding effectively to the demands of their job, they are committed to their tasks and enjoy their execution [7].

Given the important relationship between these three variables, the general objective of this study is to analyse the psychometric properties of the Nursing Stress Scale by GrayToft and Anderson (1981) [1]. The specific objectives are a) to validate the NSS scale in Spanish in a sample of nurses; b) to check the convergent validity with the job satisfaction and engagement scales; c) to evaluate the age-discriminating validity.

\section{Materials and Methods}




\subsection{Participants}

The sample consists of 180 nurses. The average age was 43.33 years with a $S D=10.26$ (ages 21-68). The average seniority in the workplace was 86.04 months (7.16 years) with $S D=99.97$ (varying from a few months to 41 years) and an average seniority in the profession of 215.48 months (17.92 years) varying from a few months to 44 years. The average number of overtime hours worked is $2.46(S D=4.99) .65 \%$ are married, $27.8 \%$ are single and $7.2 \%$ are divorced, separated or widowed. The type of contract is $51.6 \%$ fixed, $42.2 \%$ temporary and $6.2 \%$ interim. $58.9 \%$ work a rotating shift, $34.5 \%$ work a fixed morning shift and $6.6 \%$ work other shifts.

\subsection{Instruments}

Job stress: It was measured using the Nursing Stress Scale (NSS) by Gray-Toft and Anderson (1981) [1] which is composed of 34 items answered by thinking about the last six months. The items are divided into 7 subscales "death and dying patients" with 7 items, "conflict with physicians" with 5 items, "inadequate preparation" with 3 items, "lack of staff support" with 3 items, "conflict with other nurses" with 5 items, "workload" with 6 items and "uncertainty concerning treatment" with 5 items.

Engagement. It was evaluated using the reduced version (9 items) of the Ultrecht Work Engagement Scale (UWES-9) by Schaufeli \& Bakker (2003) [8]. The UWES-9 scale is confirmed to be useful in the health care setting and is also shown to be reliable, valid, and pragmatic as is its longer version [9] and shows good psychometric properties [10].

Job satisfaction. It was assessed using the short job satisfaction scale (BIAJS) by Thompson and Phua (2012) [11] which has seven items although items 2, 4 and 6 are distracting and are not analyzed. This scale is used because there are data that affirm the usefulness of using a very short job satisfaction scale to analyze this variable (Thompson and Phua, 2012) [11].

\subsection{Procedure}

The workers completed a self-report questionnaire with different socio-demographic data and the three scales mentioned above. An informed consent is signed, and the confidentiality of the answers is guaranteed.

\subsection{Statistical analysis of the data}

Exploratory analysis of the data was carried out using SPSS 21.0. A descriptive analysis, a correlation analysis and a factor analysis were performed to check the psychometric values. In addition, a Confirmatory Factor Analysis (CFA) was carried out to assess the structure of the scale. As absolute fit indexes, the approximation mean square error (RMSEA) is used which values under .08 indicative a reasonable fit and between .08 to .10 a mediocre fit [12] and as incremental fit indexes we are used the Tucker-Lewis index (TLI) that it is recommended that it be greater than .90 [13] and the comparative fit index (CFI) that the values should be approximated to .95.[14]

\section{Results}

First, the correlation analysis between the seven subscales was carried out (see Table 1 ) and then the factor analysis. The Kaiser-Meyer-Olkin test (KMO) was close to 1 (KMO $=0.84$ ) which indicates that confirmatory analysis is appropriate. In addition, the Bartlett test was significant $(\mathrm{p}<.000)$.

Table 1. Pearson correlations between the seven subscales.

\begin{tabular}{|c|c|c|c|c|c|c|c|c|}
\hline & & 1 & 2 & 3 & 4 & 5 & 6 & 7 \\
\hline & Death and dying patients & 1 & & & & & & \\
\hline 2. & Conflict with physicians & $.60^{* *}$ & 1 & & & & & \\
\hline
\end{tabular}




\begin{tabular}{|c|c|c|c|c|c|c|c|}
\hline Inadequate preparation & $.47^{* *}$ & $.49^{* *}$ & 1 & & & & \\
\hline Lack of staff support & $.20^{* *}$ & $.21^{* *}$ & $.21^{* *}$ & 1 & & & \\
\hline 5. Conflict with other nurses & $.36^{* *}$ & $.53^{* *}$ & $.39^{* *}$ & $.48^{* *}$ & 1 & & \\
\hline 6. Workload & $.50^{* *}$ & $.47^{* *}$ & $.39^{* *}$ & $.37^{* *}$ & $.44^{* *}$ & 1 & \\
\hline Uncertainty concerning treatment & $.58^{* *}$ & $.61^{* *}$ & $.57^{* *}$ & $.34^{* *}$ & $.44^{* *}$ & $.54^{* *}$ & 1 \\
\hline
\end{tabular}

Figure 1 shows the pathway diagram of the proposed model. The standardized values of the regression coefficients were appropriate because the factor loads were high and significant and all of them are significant $(\mathrm{p}<.001)$. The global adjustment indices showed the following results, with CFI $=.95$, RMSEA $=.07$ and TLI $=.90$.

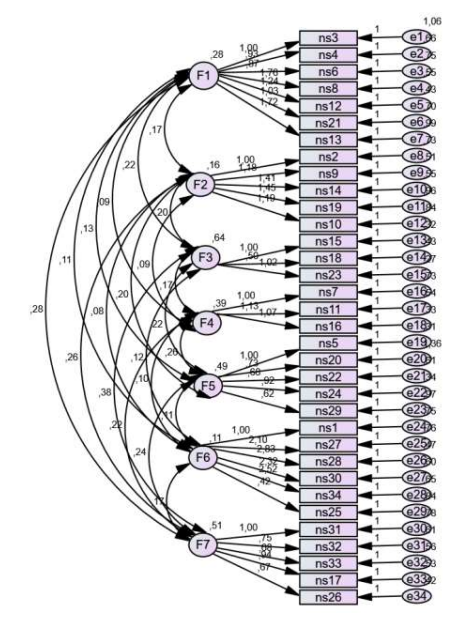

Figure 1. Confirmatory Factor Analysis (CFA) pathway diagram of the NSS Scale.

\section{Reliability}

Table 2 shows Cronbach's alpha and composite reliability for the full scale and the seven subscales of the test. The internal consistency is generally high, the composite reliability is higher because Alpha underestimates the reliability of ordinal data $[15,16]$. Since the minimum value considered adequate for composite reliability is .70 [17], the values found in subscales reflect adequate accuracy of these measures except for the "lack of staff support" scale which shows lower reliability (.63)

Table 2. Alpha de Cronbach y composite reliability (CR).

\begin{tabular}{ccc}
\hline Subscales & $\alpha$ & CR \\
\hline Death and dying patients & 0.79 & 0.80 \\
Conflict with physicians & 0.62 & 0.74 \\
Inadequate preparation & 0.75 & 0.75 \\
Lack of staff support & 0.63 \\
Conflict with other nurses & 0.78 \\
Workload & 0.72 \\
Uncertainty concerning treatment & 0.74 \\
TOTAL SCALE & 0.73 & 0.70 \\
& 0.90 \\
\hline
\end{tabular}

\section{Convergent and divergent validity}

To analyze convergent and divergent validity, correlations between engagement and job satisfaction scores were examined with the NSS subscales (see Table 3 ) and as a function of age (under and over 42 years old) (see Table 4 ).

Table 3. Correlations between job satisfaction and engagement scales and NSS subscales. 


\begin{tabular}{cccccccc}
\hline & $\mathbf{1}$ & $\mathbf{2}$ & $\mathbf{3}$ & $\mathbf{4}$ & $\mathbf{5}$ & $\mathbf{6}$ & $\mathbf{7}$ \\
\hline Job Satisfaction & $-.18^{*}$ & $-.28^{* *}$ & $-.16^{*}$ & $-.20^{* *}$ & $-.31^{* *}$ & $-.27^{* *}$ & $-.30^{* *}$ \\
Engagement & -.09 & $-.15^{*}$ & $-.19^{* *}$ & -.14 & $-.16^{*}$ & $-.15^{*}$ & $-.17^{*}$ \\
\hline$* * p<.01 ; * p<.05$ & & & & & & & \\
\hline
\end{tabular}

Table 4. Correlations between scales under 42 (lower diagonal) and over 42 (upper diagonal).

\begin{tabular}{|c|c|c|c|c|c|c|c|c|c|}
\hline & & & 1 & 2 & & 3 & 4 & 5 & 6 \\
\hline & 1. & Death and dying patients & 1 & $.59^{* *}$ & $.38^{* *}$ & $.23^{*}$ & $.29^{* *}$ & $.42^{* *}$ & $.61^{* *}$ \\
\hline & 2. & Conflict with physicians & $.63^{* *}$ & 1 & $.51^{* *}$ & $.30 * *$ & $.55^{* *}$ & $.29 * *$ & $.54^{* *}$ \\
\hline & 3. & Inadequate preparation & $.54^{* *}$ & $.49^{* *}$ & 1 & $.39 * *$ & $.46^{* *}$ & $.25^{*}$ & $.61^{* *}$ \\
\hline & 4. & Lack of staff support & .19 & .13 & .77 & 1 & $.55^{* *}$ & $.45^{* *}$ & $.32^{* *}$ \\
\hline & 5. & Conflict with other nurses & $.43^{* *}$ & $.51^{* *}$ & $.35^{* *}$ & $.41^{* *}$ & 1 & $.33^{* *}$ & $.37^{* *}$ \\
\hline & & 6. Workload & $.59^{* *}$ & $.60^{* *}$ & $.51^{* *}$ & $.30^{* *}$ & $.54^{* *}$ & 1 & $.33^{* *}$ \\
\hline 7. & Un & certainty concerning treatment & $.57^{* *}$ & $.67^{* *}$ & $.55^{* *}$ & $.36^{* *}$ & $.51^{* *}$ & $.69 * *$ & 1 \\
\hline
\end{tabular}

$$
\text { Nota. }{ }^{* *} \text { La correlación es significativa }(p<.01) \text {. }
$$

As shown in Table 3, job satisfaction correlates with all subscales, but engagement does not correlate with either "death and dying patients" or "lack of staff support". Regarding age, people under 42 years of age do not show a correlation with the "lack of staff support" subscale.

\section{Discussion}

Nursing is a profession that suffer stressful situations and it is important to have valid and reliable instruments that provide a good evaluation of that variable in a Spanish sample. Specially, it is important due to the current situation with COVID-19. Nurses have been at the frontline of the fight against this virus, which has been an added source of stress to their regular work.

This study confirms a high reliability in both the general scale and the subscales, after that, a Confirmatory Factor Analysis confirmed a seven-factor structure. Evidence of the convergent and divergent validity of the seven subscales was provided by the variable job satisfaction. Engagement was not related to the subscales "death and dying patients" and "lack of staff support". Discriminant validity (age) showed that the correlations were significant except for "lack of staff support" in the case of nurses under 42 years old. Also, "lack of staff support" has a low reliability.

One limitation of this study is the number of participants, so, for future research it is proposed that a research with more sample will be conducted. Also, more studies should be done that delve into the subscale "lack of staff support". On the other hand, in the last month of 2020 a study by Spanish authors makes a proposal for a short version of this scale, so it would be interesting to carry out a validation of the short version of the NSS [18].

Author Contributions: “Conceptualization, Marta Peña, Cristina García y Gabriela Topa; methodology and validation, Marta Peña, Cristina García y Gabriela Topa; formal analysis and investigation, Marta Peña, Cristina García y Gabriela Topa; writing - original draft preparation, Marta Peña; writing - review, editing and supervision, Cristina García y Gabriela Topa. All authors have read and agreed to the published version of the manuscript."

Funding: "This research received no external funding"

Conflicts of Interest: "The authors declare no conflict of interest"

\section{References}

1. Gray Toft, P. y Anderson, J.G. The nursing stress scale: development of an instrument. Journal of behavioural assessment, 1981, 3 (1), 11-23. http://doi.org/10.1007/BF01321348. 
2. Pathak, V., Chakraborty, T., Mukhopadhyay, S. Reliability and Validity Analysis of Modified Nursing Stress Scale for Indian Population. Journal of Nursing Measurement, 2013, 21 (2), 224-245. http://doi.org/10.1891/1061-3749.21.2.224

3. Lee, M-H., Holzemer, W.L., Faucett, J. Psychometric Evaluation of the Nursing Stress Scale (NSS) Among Chinese Nurses in Taiwan. Journal of Nursing Measurement, 2007, 15 (2), 133-144. http://doi.org/10.1891/106137407782156381

4. Preciado Serrano, M.L., Ambriz Ramos, A., Enríquez Hernández, C.B., Hernández Chávez, G. Análisis psicométrico de la escala de estrés para profesionales mexicanos de enfermería. Revista Iberoamericana de las Ciencias de la Salud, 2016, 5 (10), 1-18. http://doi.org/10.23913/rics.v5i10.35

5. Healy, C. M., y McKay, M. F. (2000). Nursing stress: the effects of coping strategies and job satisfaction in a sample of Australian nurses. Journal of Advanced Nursing, 2000, 31 (3), 681-688. http://doi.org/10.1046/j.1365-2648.2000.01323.x

6. Schaufeli WB, Salanova M, Gonzalez-Romá V, Bakker AB. The measurement of engagement and burnout: A two sample confirmatory factor analytic approach. J Happiness stud., 2002, 3, 71-92. https://doi.org/10.1023/A:1015630930326

7. Salanova, M. Organizaciones Saludables. Una aproximación desde la Psicología Positiva. En: C. Vázquez y G. Hervás (Eds.). Psicología Positiva: Bases científicas del bienestar y la resiliencia. Madrid. Alianza Editorial, 2008, pp. 403-428.

8. Schaufeli, W. B., y Bakker, A. B. Test manual for the Utrecht work engagement scale. Unpublished manuscript. Utrecht University, the Netherlands, 2003.

9. Hernández Vargas, C.I., Llorens Gumbau, S., Rodríguez Sánchez, A.M., Dickinson Bannack, M.E. Validación de la escala UWES-9 en profesionales de la salud en México. Pensamiento psicológico, 2016, 14 (2), 89-100. http://doi.org/10.11144/Javerianacali.PPSI14-2.veup

10. Schaufeli, W.B., Bakker, A.B. y Salanova, M. The measurement of work engagement with a short questionnaire. A crossnational study. Educational and psychological measurement, 2006, 66(4), 701-716. http://doi.org/10.1177/0013164405282471.

11. Thompson, E.R. y Phua F, T. A brief index of affective job satisfaction. Group and organization management, 2012, 37 (3), $75-$ 307. http://doi.org/10.1177/1059601111434201

12. MacCallum, R.C., Browne, M.W., and Sugawara, H.M. Power Analysis and Determination of Sample Size for Covariance Structure Modeling. Psychological Methods, 1996, 1 (2), 130-149. https://doi.org/10.1037/1082-989X.1.2.130

13. Bentler, P. M., \& Bonett, D. G. Significance tests and goodness of fit in the analysis of covariance structures. Psychological Bulletin, 1980, 88, 588- 606. https://doi.org/10.1037/0033-2909.88.3.588

14. Hu, L. T. \& Bentler, P. M. Cutoff criteria for fit indexes in covariance structure analysis: Conventional criteria versus new alternatives. Structural Equation Modeling: A Multidisciplinary Journal, $1999, \quad 6, \quad 1-55$. https://doi.org/10.1080/10705519909540118

15. Bentler, P. M. Alpha, dimension-free, and model-based internal consistency reliability. Psychometrika, 2009, 74, 137-143. https://doi.org/10.1007/s11336-008-9100-1.

16. Zumbo, B. D., Gadermann, A. M., \& Zeisser, C. Ordinal versions of coefficients alpha and theta for likert rating scales. Journal of Modern Applied Statistical Methods, 2007, 6 (1), 21-29. http://doi.org/10.22237/jmasm/1177992180

17. Nunnally, J.C. Psychometric theory. New York: McGraw-Hill, 1978.

18. Porcel-Gálvez, A.M, Barrientos-Trigo, S., Bermúdez-García, S., Fernández-García, E., Bueno-Ferrán, M., \& Badanta, B. The Nursing Stress Scale-Spanish Version: An Update to Its Psychometric Properties and Validation of a Short-form Version in Acute Care Hospital Settings. Int. J. Environ. Res. Public Health, 2020, 17, 8456. http://doi.org/10.3390/ijerph17228456 